\title{
Idiopathic periodic hypothermia and bizarre behaviour in the presence of occult syringomyelia
}

\author{
H.H. Gray, L.D.R. Smith and R.H. Moore
}

St Thomas's Hospital, London SE1 7EH, UK.

\begin{abstract}
Summary: Overt psychological, neurological and haematological abnormalities were present in a 35 year old Jamaican female diagnosed as having idiopathic periodic hypothermia. Although symptoms and signs were ameliorated by warming, no long term satisfactory therapeutic measure was identified. Despite extensive clinical and subsequently histological investigation no cause for the hypothermia was found although she had clinically unsuspected cervical syringomyelia.
\end{abstract}

\section{Introduction}

Hypothermia is common as a result of exposure to cold, especially in the elderly living alone. Rarely it may result from severe hypothyroidism. However it has also been described in an idiopathic form which may have a chronic relapsing course (MacLean \& Emslie-Smith, 1977). This form of hypothermia may be associated with neurological and haematological abnormalities, it has an inexorable course to death and may be associated with cerebral abnormalities such as hypothalamic degeneration and absent corpus callosum. We present a case of idiopathic periodic hypothermia associated with profound psychological derangement for which there was no apparent accountable cerebral lesion.

\section{Case report}

A 37 year old Jamaican female was admitted via a psychiatric hospital for investigation of anaemia. She had a 6 week history of ataxia, forgetfulness, auditory hallucinations and bizarre behaviour including exhibitionism and attempted arson. There was no history of epilepsy. She denied drug abuse and was on no medication. On examination she was pale, hypokinetic at rest with cerebellar ataxia, titubation and a flapping tremor of the hands. Her temperature was recorded consistently at $34-37^{\circ} \mathrm{C}$ confirmed on a low reading thermometer. She had a normochromic normocytic anaemia $(9.2 \mathrm{~g} / 1)$ but otherwise normal investigations. She improved spontaneously over 6 weeks and was

Correspondence: L.D.R. Smith B.Sc., M.B., B.S., M.R.C.P., Cardiac Department, Brompton Hospital, Fulham Road, London SW3, UK.

Accepted: 25 September 1985 discharged home for outpatient follow-up and further investigation. In outpatients she was well with persistent mild hypothermia but 5 months later she was readmitted with an acute recurrence of her bizarre behaviour on this occasion having flooded her house. She was profoundly hypothermic (rectal temperature $30.0^{\circ} \mathrm{C}$ ), disorientated and non-communicative with similar signs to her previous admission. On warming she became lucid and her neurology improved. She remained hypothermic $\left(31-35^{\circ} \mathrm{C}\right)$ during intensive investigations, all of which proved normal (see list in Results). Separate empirical therapeutic trials with steroids, thyroxine, triiodothyronine and phenobarbitone failed. After many months the ataxia and mental state deteriorated, she developed pneumonia and died. Autopsy revealed a normal brain with normal hypothalamus but a cervical C2-C8 syringomyelic cavity was noted.

\section{Results}

Haemoglobin was 7.7-8.4 g/1, MCV 97-105, platelets $89-263 \times 10^{9} / 1$. Bone marrow was generally hypocellular but with normal cell lines. Repeated electroencephalograms showed varying degrees of diffuse abnormal activity. An electromyogram during hypothermia suggested a sensorimotor neuropathy but sural nerve biopsy was normal. The following tests were normal: white count, differential, reticulocytes, haemoglobin electrophoresis, sickle test, clotting, Coomb's test, red blood cell folate, serum B12, serum iron, total iron binding capacity, iron saturation, blood urea, creatinine, calcium, amylase, electrolytes, thyroid and liver function tests, tetracosactrin tests, thyrotrophin releasing hormone test, paired 
osmolarities, urinalysis, heavy metal and drug screening, serum copper, autoantibodies, immunoglobulins, serum phytanic acid, urinary porphyrins, Kveim test, Mantoux, syphilis serology, cerebrospinal fluid cytology, chemistry and Lange curves. Repeated computed tomographic scans were normal as was an air encephalogram. The patient would not agree to formal tests of thermoregulation.

\section{Discussion}

Spontaneous hypothermia is reputedly very rare but is described in intermittent and chronic relapsing forms (MacLean \& Emslie-Smith, 1977). In the former, which is regarded by some as a form of autonomic epilepsy (Fox et al., 1973), acute episodes of hypothermia, occurring over many years, are immediately preceded by profuse sweating. Usually no cause is demonstrated although the condition has been associated with agenesis of the corpus callosum (Shapiro et al., 1969). In the latter form there are usually progressive lesions of the hypothalamus or adjacent areas of the brain (Duff et al., 1961), the hypothermia often occurring as a terminal event. We are unaware of any reported association with syringomyelia. In a case very similar to our own (Fox et al., 1970), a Jamaican male was repeatedly admitted over a 3 year period with hypothermia and altered behaviour which was later found to be due to severe gliosis of the hypothalamus. No such abnormality was found in our patient despite extensive histological studies. Only one

\section{References}

DUFF, R.S., FARRANT, P.C., LEVEAUX, V.M. \& WRAY, S.M. (1961). Spontaneous periodic hypothermia. Quarterly Journal of Medicine, 30, 329.

FOX, R.H., DAVIES, T.W., MARSH, F.P. \& URICH, H. (1970). Hypothermia in a young man with an anterior hypothalamic lesion. Lancet, ii, 185.

FOX, R.H., WILKINS, D.C., BELL, J.A., BRADLEY, R.D., BROWSE, N.L., CRANSTON, W.I., FOLEY, T.H., GILBY, E.D., HEBDEN, A., JENKINS, B.S. \& RAWLINS, M.D. (1973). Spontaneous periodic hypothermia and diencephalic epilepsy. British Medical Journal, 2, 693.

MACLEAN, D. \& EMSLIE-SMITH, D. (1977). In Accidental other case of a flapping tremor is reported (Thomas \& Green 1973), but cerebellar ataxia is common (Thomas et al., 1973: O'Brien et al., 1982).

There are two other features of note in this case. Firstly, persistent normochromic normocytic anaemia with erythroid hypoplasia and thrombocytopaenia. This has previously been described in three hypothermic patients (O'Brien et al., 1982), in two of whom a return to normal temperature corrected the anaemia. In our patient it was impossible to maintain a normal temperature and her haemoglobin was only normal transiently following transfusion. The second feature is the associated hallucinations and bizarre behaviour which resulted in her admission to psychiatric hospitals on two occasions.

Effective therapy for this condition is very difficult. Those cases thought to be due to autonomic epilepsy have had a poor response to anticonvulsants (Fox et al., 1973). A case has been described (Slotki \& Oelbaum, 1980) with no cerebral abnormalities but associated with biochemical hypothyroidism and treated unsuccessfully with thyroid replacement on the grounds of a raised thyroid stimulating hormone. Our patient underwent separate therapeutic trials of phenobarbitone, steroids and thyroid replacement with no success.

Idiopathic periodic hypothermia may not be so rare. Infrequent use of low reading thermometers and ignorance of the condition may be masking otherg cases, especially if florid psychiatric behaviour results in admission to long term mental institutions.

Hypothermia. Blackwell Scientific Publications: Oxford. O'BRIEN, H., AMESS, A.L. \& MOLLIN, D.L. (1982). Recurrent thrombocytopaenia, erythroid hypoplasia and sideroblastic anaemia associated with hypothermia. British Journal of Haematology, 51, 451.

SHAPIRO, W.R., WILLIAMS, G.H. \& PLUM, F. (1969). Spontaneous recurrent hypothermia accompanying agenesis of the corpus callosum. Brain, 92, 423.

SLOTKI, I.N. \& OELBAUM, M.H. (1980). Recurrent spontaneous hypothermia. Postgraduate Medical Journal, 56, 656.

THOMAS, D.J. \& GREEN, I.D. (1973). Periodic hypothermia. British Medical Journal, 2, 696. 